\title{
Improvement of NO Gas Sensing Properties of Polyaniline/MWCNT Composite by Photocatalytic Effect of $\mathrm{TiO}_{2}$
}

\author{
Jumi Yun, ${ }^{1}$ Sonyeo Jeon, ${ }^{2}$ and Hyung-II Kim² \\ ${ }^{1}$ Research and Education Center of Carbon Resources, Kyushu University, 6-1 Kasugakoen, Kasuga, Fukuoka 816-8580, Japan \\ ${ }^{2}$ Department of Fine Chemical Engineering and Applied Chemistry, BK21-E2M, Chungnam National University, \\ Daejeon 305-764, Republic of Korea \\ Correspondence should be addressed to Hyung-Il Kim; hikim@cnu.ac.kr
}

Received 1 August 2013; Accepted 3 September 2013

Academic Editor: Ji Sun Im

Copyright (C) 2013 Jumi Yun et al. This is an open access article distributed under the Creative Commons Attribution License, which permits unrestricted use, distribution, and reproduction in any medium, provided the original work is properly cited.

\begin{abstract}
The highly sensitive and rapid $\mathrm{NO}$ gas sensor was prepared with polyaniline/ $\mathrm{TiO}_{2} /$ carbon nanotube composites. Aniline was polymerized on the surface of carbon nanotube (p-type semiconductor) with embedding $\mathrm{TiO}_{2}$. The gas sensing property was measured by the changes of electrical resistance without or with UV irradiation to investigate the photodegradation of NO by $\mathrm{TiO}_{2}$. The photo-degraded products such as $\mathrm{HNO}_{2}, \mathrm{NO}_{2}$, and $\mathrm{HNO}_{3}$, which were adsorbed on the PANi-coated carbon nanotubes, resulted in the decreased electrical resistance in the p-type semiconductors of carbon nanotube and polyaniline. The advantages of $\mathrm{TiO}_{2}$ photocatalyst in gas sensing were apparent in the improvement in both sensitivity and response rate.
\end{abstract}

\section{Introduction}

The demand of gas sensors has been increased extensively due to the increasing numbers of power plants, waste incinerators, and combustion engines. $\mathrm{NO}_{x}$ gases such as $\mathrm{NO}, \mathrm{N}_{2} \mathrm{O}$ and $\mathrm{NO}_{2}$, which produce the nitric and nitrous acids, cause the acid rain and the photochemical smog. These $\mathrm{NO}_{x}$ gases are formed by combustion of fossil fuels at high temperature in the chemical processes. $\mathrm{NO}_{x}$ emissions generally consist of $90-95 \% \mathrm{NO}$ with the remainder being $\mathrm{N}_{2} \mathrm{O}$, and $\mathrm{NO}_{2}$ [14]. According to the American Conference of Governmental Industrial Hygienist (ACGIH), the threshold limit values (TLV) for NO is $25 \mathrm{ppm}$ [5]. Therefore, the efficient gas sensing materials have been studied widely for the detection of very low gas concentration. Gas sensing materials can be classified mainly into two types, organic and inorganic materials. The metal oxides are used as gas sensing materials for long time due to their relatively low cost, high sensitivities, rapid response times, and simple sensing method. Nevertheless, there still exist some problems such as high working temperature of $150-350^{\circ} \mathrm{C}$ for $\mathrm{SnO}_{2}$ and $673-723 \mathrm{~K}$ for $\mathrm{ZnO}$ causing the practical limits in actual applications $[6,7]$.
The conducting polymers, which work excellently at room temperature, have attracted much attention as new classes of sensing materials. Among the conducting polymers, polyaniline (PANi) is frequently used because of its ease of synthesis, unique electrical properties, environmental stability (in acidic condition), and intrinsic redox reaction [8]. Conductivity of polyaniline depends on its ability to transport charge carriers along the polymer backbone. However, the problems of conducting polymer as gas sensing materials are their inferiorities in processing ability, chemical stability, and mechanical strength [9]. The heterojunction between organic and inorganic materials has been studied in order to solve the problems in conducting polymers [10].

Carbon nanotubes (CNTs) have the extraordinary electrical and mechanical properties with one-dimensional structure [11]. The large surface area of CNTs is beneficial to the large gas absorptive capacity expecting the faster response and higher sensitivity even at lower operating temperatures $[12,13]$. The composites of PANi/CNTs have also been investigated widely as gas sensing materials by many researchers [14-16]. However, these composites still need improvement in both sensitivity and response time to be applied in 
highly efficient gas sensor. The main reason is the weak and slow interactions between sensing materials and target gas resulting in the lower sensitivity and slower response.

In this study, the modification of PANi/CNTs sensing materials was carried out with the photocatalyst $\mathrm{TiO}_{2}$ in order to induce the stronger and faster chemical reactions between target gas and $\mathrm{TiO}_{2}$. Upon exposure to UV light, electronhole pairs are generated in the conduction and valance bands of $\mathrm{TiO}_{2}$. Photo-generated holes are strong oxidants $(\sim 3.0 \mathrm{~V})$ and can completely decompose most pollutants in air and water. $\mathrm{NO}$ is oxidized by $\mathrm{TiO}_{2}$ to nitric acid $\left(\mathrm{HNO}_{3}\right)$ in air $[17,18]$. The effect of $\mathrm{TiO}_{2}$ additive on $\mathrm{NO}$ gas sensing properties of PANi/CNTs composites was studied in terms of photodegradation reaction, sensitivity, and response of gas sensors.

\section{Materials and Methods}

2.1. Preparation of $\mathrm{PANi} / \mathrm{MWCNT/TiO}$ Composite. Aniline, ammonium persulfate (APS), and hydrochloride $(\mathrm{HCl})$ were obtained from Aldrich. Aniline was distilled in vacuum before use. Multiwalled carbon nanotubes (MWCNTs) (95\% purity, average diameter $130 \pm 15 \mathrm{~nm}$ ) were obtained from Aldrich. MWCNTs were used as the template for the in situ polymerization of aniline. The polymerization of aniline was carried out in the distilled water using $\mathrm{HCl}$ as oxidant of aniline and APS as initiator. $0.5 \mathrm{~g}$ of oxyfluorinated MWCNTs was dispersed in $30 \mathrm{~mL}$ water and ultrasonicated for $1 \mathrm{~h}$ as explained in our previous works $[19,20] .0 .5 \mathrm{~mL}$ of aniline monomer was dropped into the MWCNTs dispersion and stirred continuously for $10 \mathrm{~min}$. $0.5 \mathrm{~mL}$ of $\mathrm{HCl}$ and $0.2 \mathrm{~g}$ of $\mathrm{TiO}_{2}$ (anatase phase, average particle size $<25 \mathrm{~nm}$, $99.7 \%$, Aldrich) were then added in the aniline/MWCNT mixture. $0.5 \mathrm{~g}$ of APS dissolved in $10 \mathrm{~mL}$ distilled water was slowly added in the aniline/MWCNT/TiO 2 mixture to initiate the polymerization. The polymerization was carried out for $6 \mathrm{~h}$ at $0^{\circ} \mathrm{C}$ with constant mechanical stirring. The synthesized PANi/MWCNT/TiO 2 nanocomposites were filtered and rinsed several times with the distilled water, methanol, and acetone, respectively. The nanocomposite powders were dried under vacuum at $40^{\circ} \mathrm{C}$ for $24 \mathrm{~h}$. Four different samples were prepared such as $\mathrm{PANi}, \mathrm{PANi} / \mathrm{MWCNT}, \mathrm{PANi} / \mathrm{TiO}_{2}$, and $\mathrm{PANi} / \mathrm{MWCNT} / \mathrm{TiO}_{2}$ named as PA, PC, PT, and PCT, respectively.

2.2. Measurement of Gas Sensitivity. In order to evaluate the gas sensing properties of composites, the electrical resistance was measured using a programmable electrometer (Keithley 6514). The gas sensing device was prepared by using two $\mathrm{Pt}$ electrodes and $\mathrm{SiO}_{2}$ plate as shown in previous work $[12,21]$. The electrical resistance was measured in a stainless steel chamber with a volume of $1500 \mathrm{~cm}^{3}$. The chamber was connected to gas cylinders (NO and wet air with a relative humidity of $50 \%$ ), and the gas sensor sample was placed in a sealed vacuum chamber at a pressure of $1 \times 10^{-6} \mathrm{mbar}$. Air was injected initially into the chamber in order to stabilize the electrical resistance of the sensor. The gaseous mixture containing $25 \mathrm{ppm} \mathrm{NO}$ in air was injected into the chamber at a fixed rate of $500 \mathrm{sccm}$ and the resultant change in the electrical resistance of gas sensor was measured at $22 \pm 1{ }^{\circ} \mathrm{C}$. The chamber was covered with a circulating water tube in order to maintain a constant temperature. The adsorbed gases on the gas sensor samples were removed by heating the specimens to $100^{\circ} \mathrm{C}$ at a pressure of $1 \times 10^{-6} \mathrm{mbar}$ for $5 \mathrm{~min}$ $[12,21]$. Recovery testing was carried out three times.

2.3. Characterization of Samples. Field emission scanning electron microscope (FE-SEM, Hitachi, S-5500) was used to investigate the surface morphology of the prepared gas sensors. SEM images were taken without prior treatment in order to ensure the acquisition of accurate images. X-ray diffraction patterns of the samples were obtained on an XRD apparatus (D/MAX-2200 Ultima/PC, Rigaku, Japan) in order to investigate the phases and crystal structures of $\mathrm{TiO}_{2}$.

\section{Results and Discussion}

3.1. Surface Morphologies of Samples. FE-SEM images of the surface morphologies of samples are presented in Figure 1. PA sample showed the aggregated PANi phases of the uniformsized spherical type. The average size of PANi spherical phases was measured as $193 \pm 27 \mathrm{~nm}$ (average value measured five times) by the computer program installed in FE-SEM apparatus. The uniformly coated PANi on MWCNTs was observed for PC sample as shown in Figure 1(b). The average thickness of PANi coating layer was around $23 \pm 8 \mathrm{~nm}$ considering the average diameter of MWCNTs $(130 \pm 15 \mathrm{~nm})$. PANi was also coated on $\mathrm{TiO}_{2}$ particles but was aggregated to some extent as shown in Figure 1(c). PCT sample showed the $\mathrm{TiO}_{2}$ particles dispersed on the PANi-coated MWCNTs as shown in Figure 1(d).

3.2. XRD Analysis of Samples. XRD patterns of four prepared samples are presented in Figure 2. The original carbon peaks were observed at 002 position which is attributed to the welloriented carbon structure for MWCNT [22, 23]. PA also showed the original peak of PANi clearly [24]. XRD pattern of $\mathrm{TiO}_{2}$ showed the characteristics of anatase $\mathrm{TiO}_{2}$ phase with a tetragonal structure which possessed the photocatalytic properties $[25,26]$. All XRD peaks of PCT samples can be attributed to the diffraction of $\mathrm{PANi}, \mathrm{TiO}_{2}$, and MWCNTs.

3.3. NO Gas Sensing Behavior by Resistive Response. The NO gas sensing behavior of the samples was determined by monitoring the electrical resistance and presented in Figures 3 and 4 . The resultant sensitivities were expressed as $S(\%)$ according to the following equation $[27,28]$ :

$$
S(\%)=\frac{\left(R-R_{0}\right)}{R_{0}} \times 100=\frac{\Delta R}{R_{0}} \times 100,
$$

where $R_{0}$ and $R$ are the resistance measured in air and $25 \mathrm{ppm}$ of $\mathrm{NO}$, respectively. The $\mathrm{NO}$ gas sensing behavior in the absence of UV irradiation is shown in Figure 3. The electrical resistance decreased upon NO gas exposure for all the samples in accordance with the typical characteristics of a ptype semiconductor. The decrease in the electrical resistance 


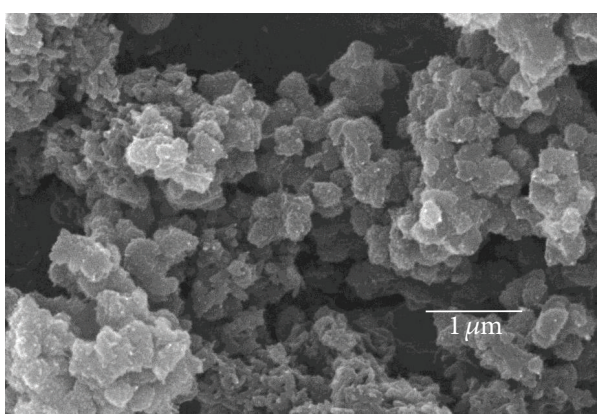

(a)

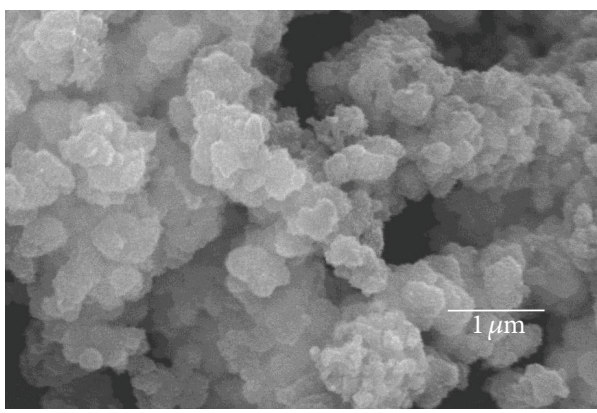

(c)

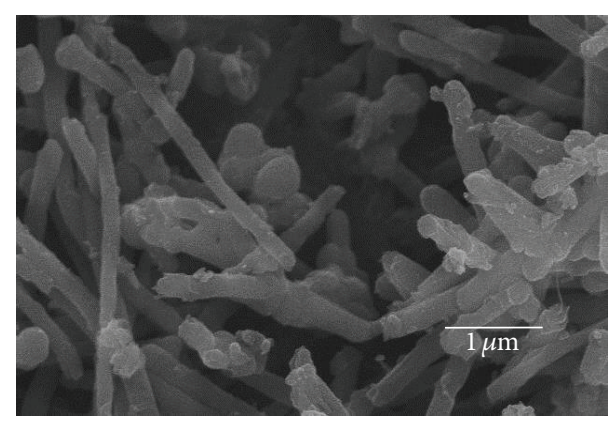

(b)

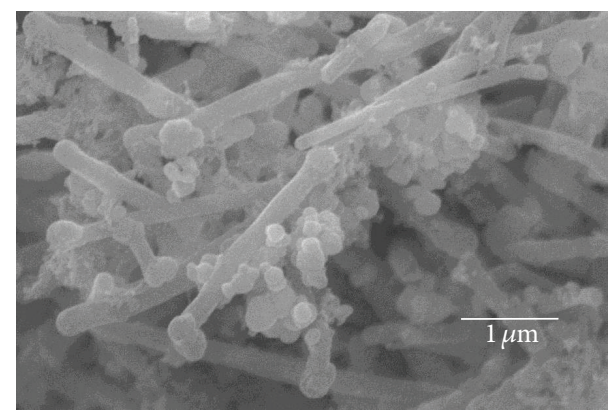

(d)

Figure 1: FE-SEM images of (a) PA, (b) PC, (c) PT, and (d) PCT samples.

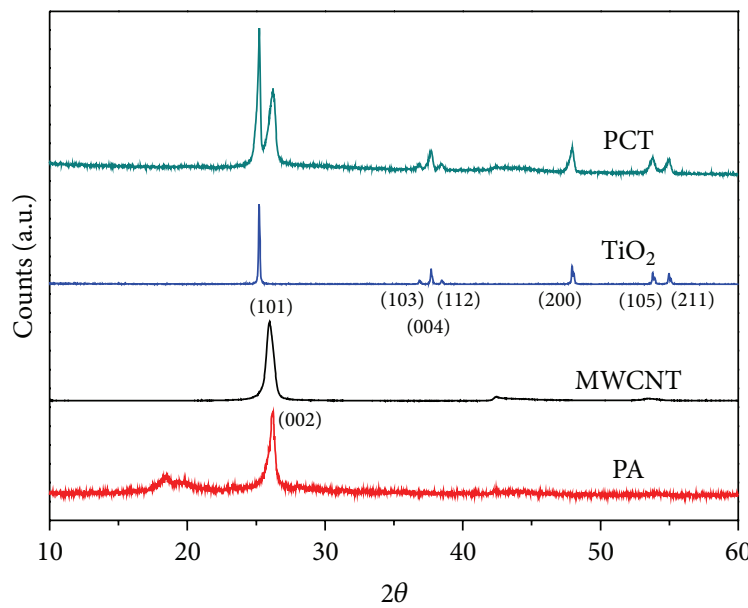

FIGURE 2: XRD patterns of the prepared samples.

is attributed to the electron charge transfer between $\mathrm{NO}$ gas and the surface of PANi/MWCNT p-type semiconductors. The electrons are known to travel from p-type semiconductor to $\mathrm{NO}$ gas (oxidizing gas) resulting in the reduced electrical resistance [29-31]. The $\mathrm{TiO}_{2}$ photocatalyst did not contribute to the NO gas sensing behavior directly because the metal oxide-based semiconductors were generally operated at high temperature $[6,7]$. However, even the composite with n-type semiconductor $\mathrm{TiO}_{2}$ showed some decrease in the electrical resistance. Among the various gas sensing materials, the highest sensitivity was observed for the PC sample which showed $13 \%$ change in the electrical resistance. This high

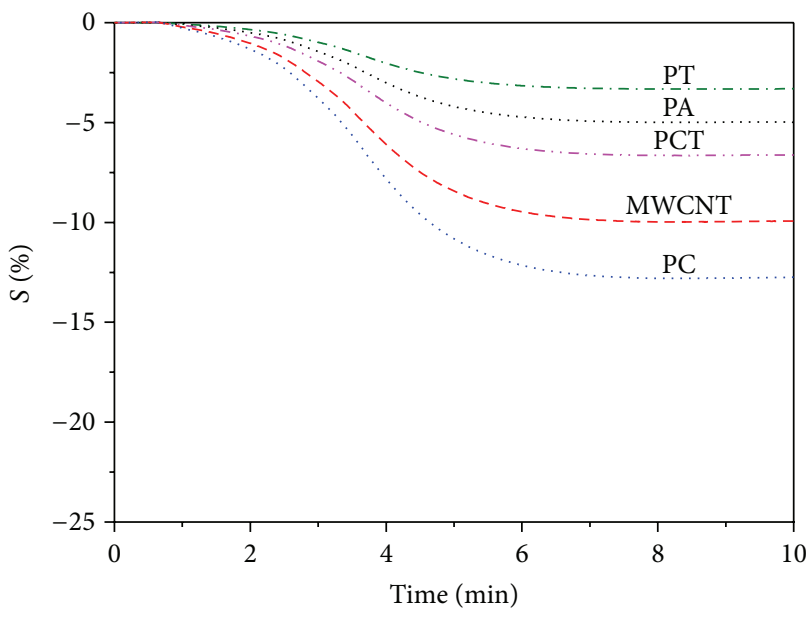

FIGURE 3: NO gas sensing behavior of various samples in the absence of UV irradiation.

sensitivity was attributed to the interaction of MWCNTs with PANi, leading to the expansion of compact PANi chains into more stretched conformations and resulting in the decrease of electric resistance. The improved gas sensing performance of PANi/CNT composite was also studied by the other group [32].

Totally different trends in the NO gas sensing behavior were observed under UV irradiation as shown in Figure 4. The addition of $\mathrm{TiO}_{2}$ in the gas sensing material improved the sensitivity of NO gas sensor significantly. PCT sample showed the highest sensitivity indicating $23.5 \%$ change in 


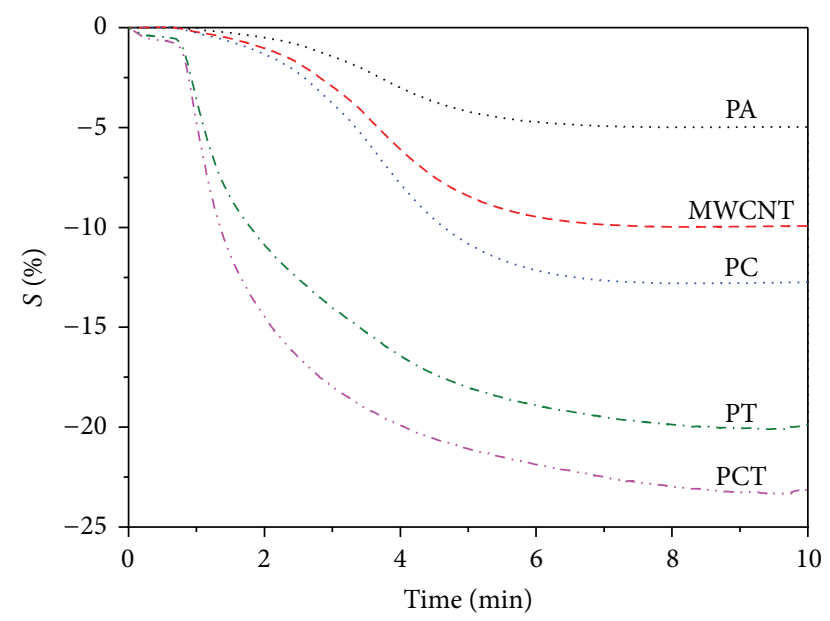

FIGURE 4: NO gas sensing behavior of various samples under UV irradiation.

the electrical resistance. This result was attributed to the decomposition of $\mathrm{NO}$ gas by the photocatalytic reaction of $\mathrm{TiO}_{2}$ under UV irradiation [30,33] as follows:

$$
\begin{aligned}
& \mathrm{TiO}_{2}+h v \longrightarrow \mathrm{e}_{\mathrm{CB}}{ }^{-}+h_{\mathrm{VB}}{ }^{+} \\
& h_{\mathrm{VB}}{ }^{+}+\mathrm{H}_{2} \mathrm{O}_{\mathrm{ads}} \longrightarrow \mathrm{HO}_{\mathrm{ads}}{ }^{+}+\mathrm{H}^{+} \\
& h_{\mathrm{VB}}{ }^{+}+\mathrm{HO}_{\mathrm{ads}}{ }^{-} \longrightarrow \mathrm{HO}_{\mathrm{ads}}{ }^{\bullet} \\
& \mathrm{e}_{\mathrm{CB}}{ }^{-}+\mathrm{O}_{2 \mathrm{ads}} \longrightarrow \mathrm{O}_{2 \mathrm{ads}}{ }^{\bullet}
\end{aligned}
$$

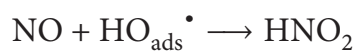

$$
\begin{aligned}
& \mathrm{HNO}_{2}+\mathrm{HO}_{\mathrm{ads}} \stackrel{\bullet}{\longrightarrow} \mathrm{NO}_{2}+\mathrm{H}_{2} \mathrm{O} \\
& \mathrm{NO}_{2}+\mathrm{HO}_{\mathrm{ads}} \cdot \overrightarrow{\mathrm{HNO}_{3}} \\
& \mathrm{NO}+\mathrm{O}_{2 \mathrm{ads}}{ }^{\cdot-} \longrightarrow \mathrm{NO}_{3}{ }^{-}
\end{aligned}
$$

The electrons in $\mathrm{TiO}_{2}$ are excited from the valence band to the conduction band under UV irradiation, generating the electron-hole pairs, which can recombine or initiate the redox reactions. Holes are trapped by water $\left(\mathrm{H}_{2} \mathrm{O}\right)$ or hydroxyl groups $\left(\mathrm{OH}^{-}\right)$that are adsorbed on the surface of material, producing the hydroxyl radicals $\left(\mathrm{OH}^{\bullet}\right)$. The electrons reduce the adsorbed oxygen, resulting in the formation of superoxide ions $\left(\mathrm{O}_{2}{ }^{\circ-}\right)$. Therefore, $\mathrm{OH}$ and $\mathrm{O}$ groups on the surface of $\mathrm{TiO}_{2}$ play an important role in $\mathrm{NO}$ adsorption and oxidation [30].

Three different states are observed during the photocatalytic oxidation of NO $[34,35]$. The primary oxidation product is $\mathrm{HNO}_{2}$ in the initial state. In the transient state, $\mathrm{HNO}_{2}$ is oxidized to $\mathrm{NO}_{2}$, which is subsequently oxidized to $\mathrm{HNO}_{3}$. As a result, the products of $\mathrm{NO}$ decomposition are $\mathrm{HNO}_{2}$, $\mathrm{NO}_{2}$, and $\mathrm{HNO}_{3}$. The photocatalytic decomposition products are adsorbed effectively on the PANi-coated MWCNTs because of the high gas adsorption capacity by high specific surface areas and pore volume of MWCNTs $[12,13]$ and the hydrophilicity of PANi polymer [36]. Although MWCNT

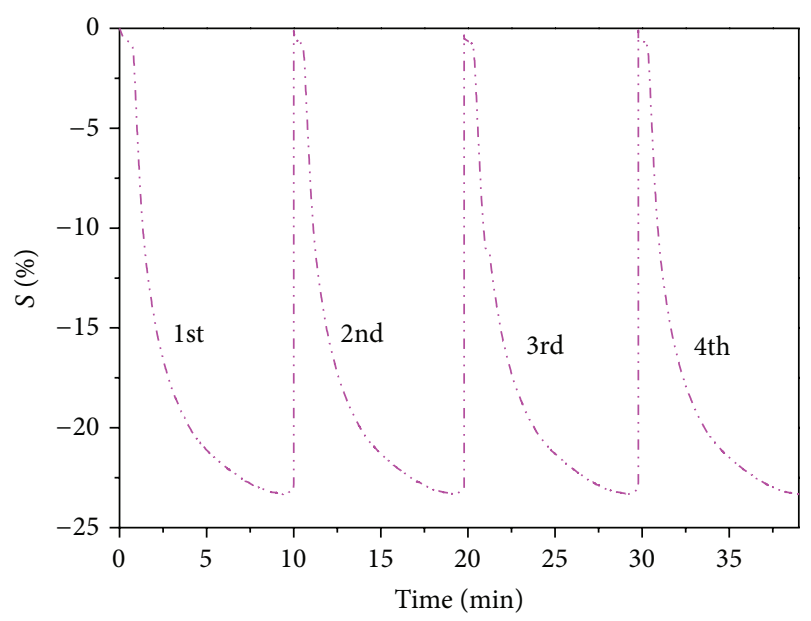

FIgURE 5: Reproducibility of NO gas sensing behavior of PCT sample under UV irradiation.

provide the high porosity for gas adsorption, its hydrophobicity results in the poor adsorption of hydrophilic gases such as $\mathrm{HNO}_{2}, \mathrm{NO}_{2}$, and $\mathrm{HNO}_{3}$. Therefore, the composite with PANi is beneficial for the adsorption of hydrophilic gases resulting in the decreased electrical resistance and the increased sensitivity of gas sensor. The photocatalytic activity of $\mathrm{TiO}_{2}$ is maximized due to the effective suppression of the electron-hole pairs combination by conductive MWCNT and PANi. The large and rapid changes in electrical resistance upon NO gas adsorption under UV irradiation are attributed to the combination effects of improved conductivity of PANi/MWCNT composite and effective adsorption of photocatalytic decomposition products on MWCNTs.

The decomposition products, which were adsorbed on the sensing materials, were indirectly investigated by monitoring the variation in $\mathrm{pH}$ of the desorbing solution. The desorbed acidic $\mathrm{HNO}_{3}$ may reduce the $\mathrm{pH}$ of desorbing solution. The adsorbed products were dissolved in water $(20 \mathrm{~mL})$ by putting PCT sample $(0.2 \mathrm{~g})$ under agitation at room temperature for $4 \mathrm{~h}$. The $\mathrm{pH}$ of PCT suspension changed from 7.2 to 4.8 after desorbing the adsorbed products on PCT sample, indicating that the acidic molecules were adsorbed on the porous MWCNTs.

3.4. Recovery Properties of Gas Sensor. Figure 5 presents the reproducibility of the PCT gas sensor which showed the highest gas sensitivity. Perfect reproducibility was observed for the PCT sample due to the excellent gas desorption properties during the recovery process, which was performed at lower temperature of $100^{\circ} \mathrm{C}$. The adsorption of $\mathrm{NO}$ gas on the PCT sample with relatively weak interaction was beneficial to the excellent recovery property of gas sensor.

\section{Conclusions}

The high-performance NO gas sensor was prepared by $\mathrm{PANi} / \mathrm{MWCNT} / \mathrm{TiO}_{2}$ composite using in situ polymerization method. The gas sensing behavior was evaluated by 
measuring the changes in electrical resistance upon $\mathrm{NO}$ gas adsorption without or with UV irradiation to investigate the photodegradation effects of $\mathrm{NO}$ gas by $\mathrm{TiO}_{2}$. The electrical resistance was decreased by p-type semiconductors of MWCNT and polyaniline. The $\mathrm{TiO}_{2}$ photocatalyst improved both sensitivity and response of the PANi/MWCNT/TiO gas sensor greatly. The improvement in gas sensing behavior was attributed to the effective photocatalytic decomposition of $\mathrm{NO}$ gas into $\mathrm{HNO}_{2}, \mathrm{NO}_{2}$, and $\mathrm{HNO}_{3}$ acidic gases by $\mathrm{TiO}_{2}$ and the effective adsorption on the hydrophilic sites of PANi-coated MWCNTs resulting in the decreased electrical resistance. $\mathrm{PANi} / \mathrm{MWCNT} / \mathrm{TiO}_{2}$ gas sensor showed excellent reproducibility in gas sensing behavior during the recovery process at lower temperature of $100^{\circ} \mathrm{C}$.

\section{References}

[1] B. T. Marquis and J. F. Vetelino, "A semiconducting metal oxide sensor array for the detection of $\mathrm{NO}_{x}$ and $\mathrm{NH}_{3}$," Sensors and Actuators B, vol. 77, no. 1-2, pp. 100-110, 2001.

[2] L. Chen and S. C. Tsang, "Ag doped $\mathrm{WO}_{3}$-based powder sensor for the detection of NO gas in air," Sensors and Actuators B, vol. 89, no. 1-2, pp. 68-75, 2003.

[3] W. Zhang, H. Uchida, T. Katsube, T. Nakatsubo, and Y. Nishioka, "A novel semiconductor NO gas sensor operating at room temperature," Sensors and Actuators B, vol. 49, no. 1-2, pp. 58-62, 1998.

[4] P. Schmidt-Zhang, W. Zhang, F. Gerlach, K. Ahlborn, and U. Guth, "Electrochemical investigations on multi-metallic electrodes for amperometric NO gas sensors," Sensors and Actuators B, vol. 108, no. 1-2, pp. 797-802, 2005.

[5] M. Penza, C. Martucci, and G. Cassano, " $\mathrm{NO}_{x}$ gas sensing characteristics of $\mathrm{WO}_{3}$ thin films activated by noble metals (Pd, $\mathrm{Pt}, \mathrm{Au}$ ) layers," Sensors and Actuators B, vol. 50, no. 1, pp. 52-59, 1998.

[6] R. C. Ionescu, A. Vancu, and F. Buta, "Diode-like $\mathrm{SnO}_{2}$ gas detection devices," Sensors and Actuators B, vol. 43, no. 1-3, pp. 126-131, 1997.

[7] T. Seiyama, H. Futata, F. Era, and N. Yamazoe, "Detection of gases by an activated semiconductive sensor," Journal of Materials Science, vol. 8, pp. 63-65, 1972.

[8] J. B. Yadav, S. V. Jhadav, R. K. Puri, and V. Puri, "Properties of vacuum evaporated vapour chopped polyaniline thin film: effect of synthesis method," Journal of Physics, vol. 114, no. 1, Article ID 012037, 2008.

[9] M. Matsuguchi, A. Okamoto, and Y. Sakai, "Effect of humidity on $\mathrm{NH}_{3}$ gas sensitivity of polyaniline blend films," Sensors and Actuators B, vol. 94, no. 1, pp. 46-52, 2003.

[10] D. S. Dhawale, R. R. Salunkhe, U. M. Patil, K. V. Gurav, A. M. More, and C. D. Lokhande, "Room temperature liquefied petroleum gas (LPG) sensor based on p-polyaniline/n- $-\mathrm{TiO}_{2}$ heterojunction," Sensors and Actuators B, vol. 134, no. 2, pp. 988-992, 2008.

[11] S. M. Lee, K. H. An, Y. H. Lee, G. Seifert, and T. Frauenheim, "A hydrogen storage mechanism in single-walled carbon nanotubes," Journal of the American Chemical Society, vol. 123, no. 21, pp. 5059-5063, 2001

[12] J. S. Im, S. C. Kang, B. C. Bai et al., "Thermal fluorination effects on carbon nanotubes for preparation of a high-performance gas sensor," Carbon, vol. 49, no. 7, pp. 2235-2244, 2011.
[13] J. S. Im, S. C. Kang, B. C. Bai, J. K. Suh, and Y. S. Lee, "Effect of thermal fluorination on the hydrogen storage capacity of multiwalled carbon nanotubes," International Journal of Hydrogen Energy, vol. 36, no. 2, pp. 1560-1567, 2011.

[14] S. Srivastava, S. S. Sharma, S. Agrawal, S. Kumar, M. Singh, and Y. K. Vijay, "Study of chemiresistor type CNT doped polyaniline gas sensor," Synthetic Metals, vol. 160, no. 5-6, pp. 529-534, 2010.

[15] P. Lobotka, P. Kunzo, E. Kovacova et al., "Thin polyaniline and polyaniline/carbon nanocomposite films for gas sensing," Thin Solid Films, vol. 519, no. 12, pp. 4123-4127, 2011.

[16] K. P. Yoo, K. H. Kwon, N. K. Min, M. J. Lee, and C. J. Lee, "Effects of $\mathrm{O}_{2}$ plasma treatment on $\mathrm{NH}_{3}$ sensing characteristics of multiwall carbon nanotube/polyaniline composite films," Sensors and Actuators B, vol. 143, no. 1, pp. 333-340, 2009.

[17] T. Ueda, K. Takahashi, F. Mitsugi, and T. Ikegami, "Preparation of single-walled carbon nanotube/ $/ \mathrm{TiO}_{2}$ hybrid atmospheric gas sensor operated at ambient temperature," Diamond and Related Materials, vol. 18, no. 2-3, pp. 493-496, 2009.

[18] S. H. Chien, M. C. Kuo, C. H. Lu, and K. N. Lu, "Spectroscopic studies of $\mathrm{NO}$ reduction on $\mathrm{Pt} / \mathrm{TiO}_{2}$ catalysts," Catalysis Today, vol. 97, no. 2-3, pp. 121-127, 2004.

[19] J. Yun, J. S. Im, Y. S. Lee, and H. I. Kim, "Effect of oxyfluorination on electromagnetic interference shielding behavior of MWCNT/PVA/PAAc composite microcapsules," European Polymer Journal, vol. 46, no. 5, pp. 900-909, 2010.

[20] J. Yun, J. S. Im, Y. S. Lee, T. S. Bae, Y. M. Lim, and H. I. Kim, "pH and electro-responsive release behavior of MWCNT/PVA/PAAc composite microcapsules," Colloids and Surfaces A, vol. 368, no. 1-3, pp. 23-30, 2010.

[21] J. S. Im, S. C. Kang, S. H. Lee, and Y. S. Lee, "Improved gas sensing of electrospun carbon fibers based on pore structure, conductivity and surface modification," Carbon, vol. 48, no. 9, pp. 2573-2581, 2010.

[22] B. Y. Jibril and A. Y. Atta, "Activated carbon incorporated with first-row transition metals as catalysts in hydrogen production from propane," International Journal of Hydrogen Energy, vol. 36, no. 10, pp. 5951-5959, 2011.

[23] J. S. Im, M. I. Kim, and Y. S. Lee, "Preparation of PAN-based electrospun nanofiber webs containing $\mathrm{TiO}_{2}$ for photocatalytic degradation," Materials Letters, vol. 62, no. 21-22, pp. 3652-3655, 2008.

[24] H. Wang, R. Wang, L. Wang, and X. Tian, "Preparation of multicore/single-shell $\mathrm{OA}-\mathrm{Fe}_{3} \mathrm{O}_{4} / \mathrm{PANI}$ bifunctional nanoparticles via miniemulsion polymerization," Colloids and Surfaces A, vol. 384, no. 1-3, pp. 624-629, 2011.

[25] S. K. Lee, E. Jeong, J. S. Im, and Y. S. Lee, "Electrochemical characterization of hybrid semiconductor-based, dye-sensitized solar cells," Korean Journal of Chemical Engineering, vol. 49, pp. 175-180, 2011.

[26] S. K. Lee and Y. S. Lee, "Energy conversion efficiency of $\mathrm{TiO}_{2}$ dye-sensitized solar cells with $\mathrm{WO}_{3}$ additive," Journal of the Korean Industrial and Engineering Chemistry, vol. 22, no. 1, pp. 26-30, 2011.

[27] M. Penza, R. Rossi, M. Alvisi et al., "Pt- and Pd-nanoclusters functionalized carbon nanotubes networked films for sub-ppm gas sensors," Sensors and Actuators B, vol. 135, no. 1, pp. 289-297, 2008.

[28] H. Q. Nguyen and J. S. Huh, "Behavior of single-walled carbon nanotube-based gas sensors at various temperatures of treatment and operation," Sensors and Actuators B, vol. 117, no. 2, pp. 426-430, 2006. 
[29] T. Ueda, M. M. H. Bhuiyan, H. Norimatsu, S. Katsuki, T. Ikegami, and F. Mitsugi, "Development of carbon nanotubebased gas sensors for $\mathrm{NO}_{x}$ gas detection working at low temperature," Physica E, vol. 40, no. 7, pp. 2272-2277, 2008.

[30] D. H. Nguyen, V. Q. Nguyen, Y. S. Cho, and D. Kim, "Porous single-wall carbon nanotube films formed by in Situ arcdischarge deposition for gas sensors application," Sensors and Actuators B, vol. 135, no. 2, pp. 656-663, 2009.

[31] P. Bondavalli, P. Legagneux, and D. Pribat, "Carbon nanotubes based transistors as gas sensors: state of the art and critical review," Sensors and Actuators B, vol. 140, no. 1, pp. 304-318, 2009.

[32] S. Srivastava, S. S. Sharma, S. Kumar, S. Agrawal, M. Singh, and Y. K. Vijay, "Characterization of gas sensing behavior of multi walled carbon nanotube polyaniline composite films," International Journal of Hydrogen Energy, vol. 34, no. 19, pp. 8444-8450, 2009.

[33] G. Peng, E. Trock, and H. Haick, "Detecting simulated patterns of lung cancer biomarkers by random network of singlewalled carbon nanotubes coated with nonpolymeric organic materials," Nano Letters, vol. 8, no. 11, pp. 3631-3635, 2008.

[34] J. Andzelm, N. Govind, and A. Maiti, "Nanotube-based gas sensors-role of structural defects," Chemical Physics Letters, vol. 421, no. 1-3, pp. 58-62, 2006.

[35] L. Valentini, F. Mercuri, I. Armentano et al., "Role of defects on the gas sensing properties of carbon nanotubes thin films: experiment and theory," Chemical Physics Letters, vol. 387, no. 4-6, pp. 356-361, 2004.

[36] M. A. Molina, C. R. Rivarola, and C. A. Barbero, "Effect of copolymerization and semi-interpenetration with conducting polyanilines on the physicochemical properties of poly $(\mathrm{N}-$ isopropylacrylamide) based thermosensitive hydrogels," European Polymer Journal, vol. 47, no. 10, pp. 1977-1984, 2011. 

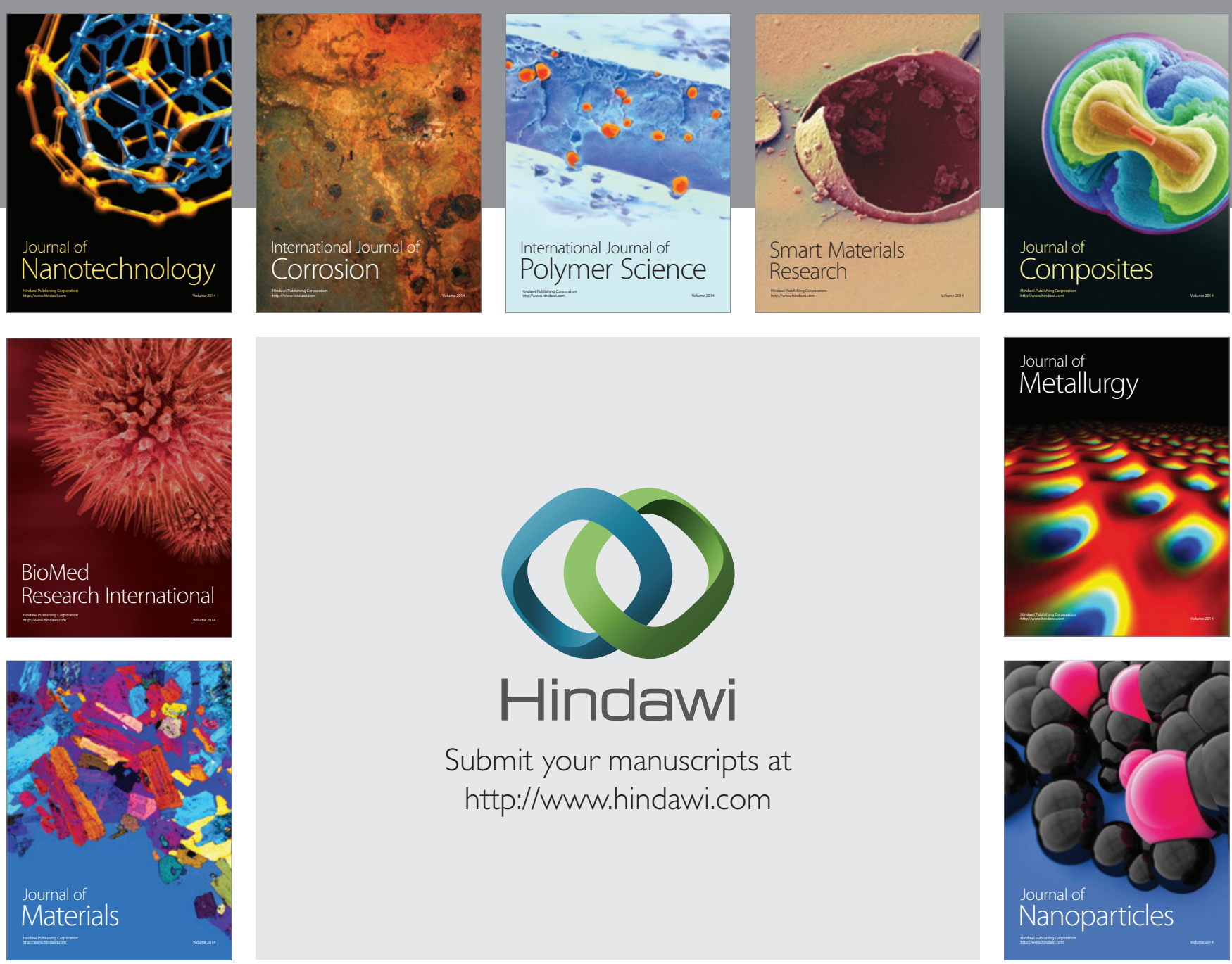

Submit your manuscripts at http://www.hindawi.com
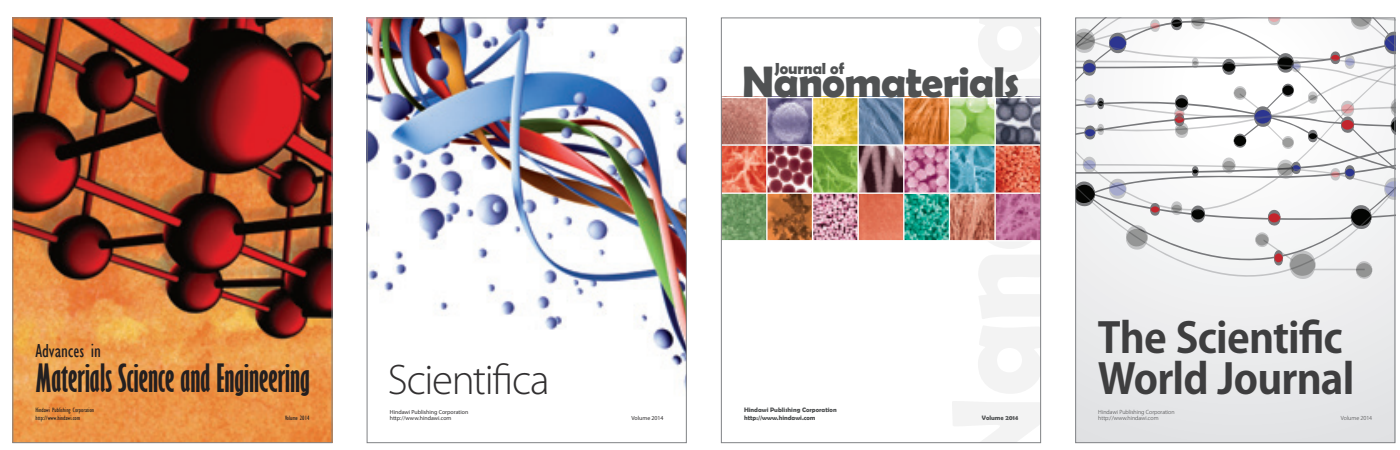

\section{The Scientific World Journal}
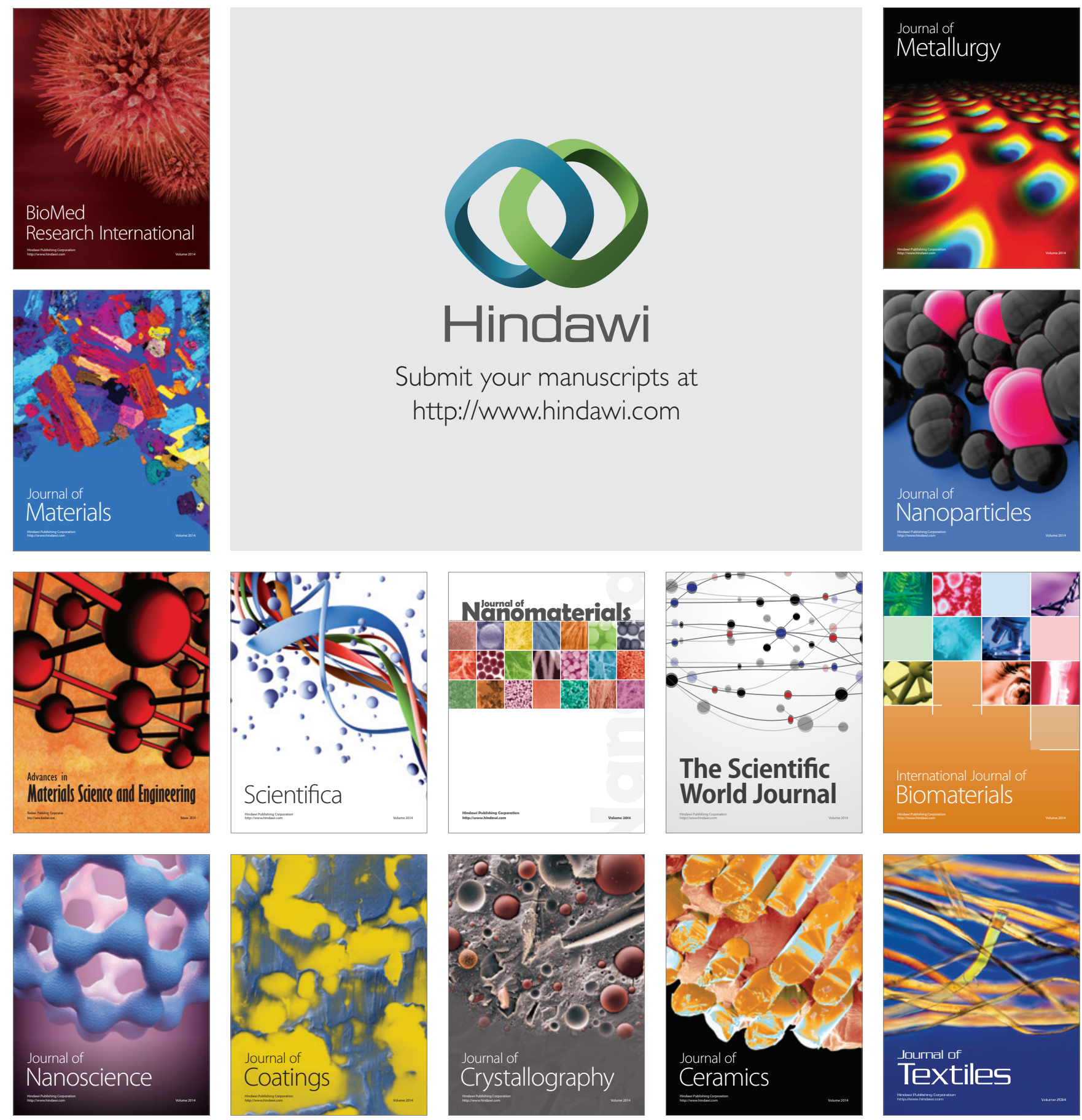